\title{
Denominaciones de origen, lexicología y desarrollo regional
}

\author{
María del Carmen Arana Courrejolles \\ Departamento Académico de Linguiistica
}

\section{CONCEPTO DE DENOMINACIONES DE ORIGEN}

El concepto de denominaciones de origen está contemplado dentro de la Ley de Propiedad Industrial D.L. No 823, Art. 219, que a la letra dice: "Se entenderá por denominación de origen, aquella que utilice el nombre de una región o un lugar geográfico del país que sirva para designar un producto originario del mismo y cuya calidad o características se deba exclusiva o esencialmente a los factores naturales y humanos del lugar". Concepto similar está establecido en la Decisión 344 del Grupo Andino en su Art. 129, que reconoce como denominación de origen:

un área geográfica determinada utilizada para designar un producto originario de ellagy cuyascuaracteristieas sedenen exclusivamente al medio geográfico en el que se produce, incluidos los factores naturales y humanos.

Así pues hay una total coincidencia entre lo que establece la ley peruana y lo normado en el Grupo Andino, coincidiendo ambas en lo esencial del concepto de denominación de origen que es el nexo entre el origen geográfico y las características del producto o servicio.

La denominación de origen es también una categoría particular de indicación de procedencia por cuanto además de indicar que un producto o servicio es originario de un país o lugar específico, las cualidades o características del producto se deben exclusiva o esencialmente al medio geográfico, incluidos los factores naturales y humanos. Los factores naturales son tales como: latitud, 
altitud, declive, textura, composición del suelo, precipitación pluviométrica, nivel térmico, vientos, flora natural entre otros) y los factores humanos se refiere a aquellos sobre los cuales el hombre tiene influencia directa tales como; prácticas culturales del lugar, conocimientos tradicionales de cultivo, conservación y producción, portaingertos, sistemas de conducción y poda, de vinificación o añejamiento entre otros.

\section{PAPEL DE LAS DENOMINACIONES DE ORIGEN}

Las denominaciones de origen cumplen la función de designar con la denominación de origen al producto, identificando su origen geográfico; asimismo informan al consumidor que el producto designado por ella tiene cualidades y calidades particulares que resultan de esa relación estrecha, entre las condiciones naturales del lugar geográfico de un lado y de otro los usos tradicionales aplicados por los hombres del lugar a su producción.

\section{TITULARIDAD DE LAS DENOMINACIONES DE ORIGEN}

En nuestra ley de Propiedad Industrial, D.L. 823, artículo 218, la titularidad de las denominaciones de origen, pertenecen al estado peruano; en otras legislaciones perteneen a la colectividad nacional oregional según el caso. La

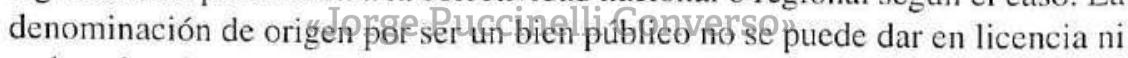
ceder, ni embargar, etc., es decir tiene carácter inalienable e imprescriptible. Su administración, cuidado y conservación corresponde a la autoridad pública y al estado.

\section{USO DE LAS DENOMINACIONES DE ORIGEN}

Sin embargo el derecho a usar comercialmente una denominación de origen puede ser dado a particulares, que cumplan una serie de requisitos; generalmente se reconoce que todos los productores que operen en la zona delimitada al declararse la denominación de origen, tienen el derecho de usarla siempre que cumplan con determinados requisitos y respeten las condiciones que establece la ley. 


\section{VENTAJAS DE LAS DENOMINACIONES DE ORIGEN}

El establecimiento de una protección a las denominaciones de origen proporciona una serie de ventajas tanto para los pobladores del lugar como para el país. Agrega valor económico al producto y da valor patrimonial a la producción originaria que use una determinada denominación de origen. No permite que otros productores que no están en la zona la utilicen. Contribuye a preservar las particularidades de las técnicas de extracción, producción y/o elaboración, según los casos, que se constituyen en patrimonio de cada región o país. Estimula y mejora la calidad de los productos, porque los productores son más cuidadosos con preservar y mejorar la cualidades de sus productos; permite ganar mercado y al consumidor le posibilita una mayor confianza para decidir su compra, porque reconoce que hay calidad; la denominación de origen es un sello de garantía que da una mayor facilidad al marketing, promueve las exportaciones, es un apoyo a la pequeña y la mediana empresa agrícola o artesanal, posibilitando un esfuerzo conjunto para mejorar el acceso al mercado nacional, al mercado andino y en genefal al mercado mundial.

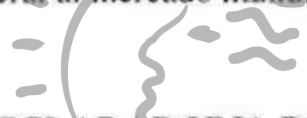

\section{REQUISITO PARA DECLARAR UNA DENOMINACION DE ORIGEN}

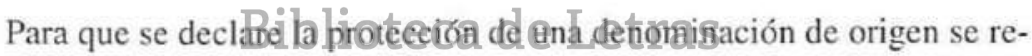
quiere de una investigacién peria indenendientementede los requisitos formales que establece la ley; está investigación busca; distinguir y delimitar un área geográfica;

- Que los productos gocen de una calidad determinada que se deba a su origen geográfico;

- Que las calidades del producto tengan un reconocimiento constatado por los lugareños y por los usuarios y consumidores.

\section{DENOMINACIONES DE ORIGEN RECONOCIDAS}

Actualmente en el Perú hay una sola denominación de origen reconocida la palabra Pisco; sin embargo estimamos que esta situación puede revertirse, lográndose que muchos nombres geográficos puedan ser reconocidos como denominaciones de origen, entre otros pueden ser: Vinos de Ica, Cerámica de 
Nazca, Guinda de Huaura, Cerámica de Chulucanas, Queso de Ambar, Salchicha de Huacho, Aceituna de Acari (Arequipa) y plátano de Mala o Maleño, etc. Se precisa de una investigación científica con la participación de las universidades, para lograr los resultados necesarios que permitan a las autoridades el reconocimiento y la protección de denominaciones de origen, para beneficio de los productores determinadas áreas geográficas.

En esta investigación es imprescindible la participación de lingüistas, para realizar con metodologías científicas la descripción y análisis de las probables denominaciones de origen, determinando su etimologia, su significado, estableciendo si es una palabra original o constituye un americanismo, los productos que distingue, características de fabricación, uso ancestrales, análisis y vinculaciones de términos que describen el conocimiento o producción de esa zona constituyendo un campo léxico que demuestre que ese producto y su proceso productivo tiene una práctica tradicional, con aplicaciones particulares del lugar.

\section{PARTICIPACION DE LOS LINGÜISTAS}

La labor científica lexicológica es importante para el establecimiento de las características de las prácticas culturales tradicionales, de los conocimientos ancestrales empleados por los produetores o afesanos del lugar, así como de

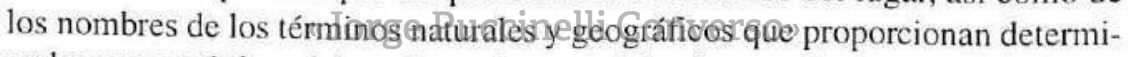
nadas características del producto. La metodología a emplearse estaría dada por el estudio científico con base a las técnicas de la lingüística, que tiene dos fases: la recolección del material léxico y el análisis léxico-semántico. La primera se inicia con la recolección de la información obtenida en la zona, para ello se aplican encuestas y cuestionarios a un universo de personas (informantes) elegidos al azar en el lugar, las entrevistas son formuladas sobre la base de los materiales y objetos que usan los pobladores así como sobre las técnicas y procedimientos que ellos aplican; la información es recogida en fichas léxicas a partir de las cuales se construye un Corpus. Los enunciados orales, ordenados y constatados, de las personas de la zona (informantes) son parte del Corpus que contiene una información confirmada y verificada. A partir de este momento (segunda fase) se realiza el análisis lexicológico, primero se establecen relaciones interlexicales entre las unidades léxicas por pares, luego se organizan los términos (unidades léxicas) en campos léxicos y finalmente se aplica el análisis semántico para identificar los conceptos o significados que corresponden a los 
términos que servirán de base para construir las definiciones de cada denominación con inclusión con todos los rasgos del contenido. El resultado es un vocabulario científico de las palabras que utilizan los pobladores de una zona, tanto de sus objetos y productos como de su técnica y actividades todo lo cual es transmitido oralmente.

Con relación a los nombres geográficos, es importante el establecimiento del origen de los topónimos, si pertenecen al quechua, al aimara, a otra lengua originaria del Perú, o al español, identificar sus modificaciones en el tiempo, recogiendo sus características locales para darle una mayor autenticidad, luego se agrega la definición geográfica que describe la zona y señala sus límites, en algunos casos se agrega alguna característica peculiar del lugar.

Estos análisis deben ser complementados por el análisis semántico para determinar con precisión el significado de las denominaciones de origen y su vinculación con los productos y/o técnicas ancestrales.

\section{IMPORTANCIA DE LAS DENOMINACIONES DE ORIGEN PARA EL DESARROLLO REGIONAL}

Como hemos visto en los puntos anteriores las denominaciones de origen

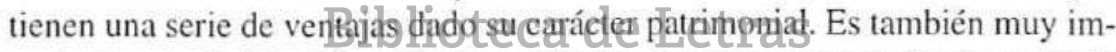
portante para la identificación de produetos-que tengan su razón de ser en la inmensa riqueza ecológica con que cuenta el Perú.

Conlleva la promoción de la producción de bienes originarios y típicos que se hacen en el Perú, debido a su pasado ancestral, además de buscar evitar que los nombres geográficos pierdan su carácter de denominaciones de origen debido al uso indiscriminado de la competencia y se conviertan ya sea en genéricos o en parte de marcas ajenas se evita así que se pierda el carácter de patrimonio nacional o regional y se cause confusión en los consumidores sobre la procedencia, el origen y la calidad de los productos.

La importancia de su protección para el desarrollo regional es evidente porque los productores regionales tendrían en sus manos un patrimonio vinculado con su geografía, para poder mejorar sus niveles productivos e incrementar su comercio tanto dentro del Perú como con el Grupo Andino o a nivel mundial. 